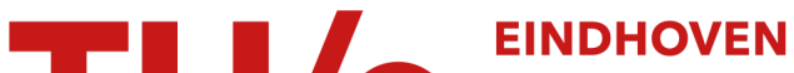 UNIVERSITY OF TECHNOLOGY
}

\section{A 13.56MHz RFID system based on organic transponders}

\section{Citation for published version (APA):}

Cantatore, E., Geuns, T. C. T., Gruijthuijsen, A. F. A., Gelinck, G. H., Drews, S., \& Leeuw, de, D. M. (2006). A 13.56MHz RFID system based on organic transponders. In Proceedings of the IEEE International Solid-State Circuits Conference 2006 (ISSCC 2006), 6-9 February 2006, San Francisco, California (pp. 15.2-1/10). Institute of Electrical and Electronics Engineers. https://doi.org/10.1109/ISSCC.2006.1696147

DOI:

10.1109/ISSCC.2006.1696147

Document status and date:

Published: 01/01/2006

\section{Document Version:}

Publisher's PDF, also known as Version of Record (includes final page, issue and volume numbers)

\section{Please check the document version of this publication:}

- A submitted manuscript is the version of the article upon submission and before peer-review. There can be important differences between the submitted version and the official published version of record. People interested in the research are advised to contact the author for the final version of the publication, or visit the DOI to the publisher's website.

- The final author version and the galley proof are versions of the publication after peer review.

- The final published version features the final layout of the paper including the volume, issue and page numbers.

Link to publication

\section{General rights}

Copyright and moral rights for the publications made accessible in the public portal are retained by the authors and/or other copyright owners and it is a condition of accessing publications that users recognise and abide by the legal requirements associated with these rights.

- Users may download and print one copy of any publication from the public portal for the purpose of private study or research.

- You may not further distribute the material or use it for any profit-making activity or commercial gain

- You may freely distribute the URL identifying the publication in the public portal.

If the publication is distributed under the terms of Article 25fa of the Dutch Copyright Act, indicated by the "Taverne" license above, please follow below link for the End User Agreement:

www.tue.nl/taverne

Take down policy

If you believe that this document breaches copyright please contact us at:

openaccess@tue.nl

providing details and we will investigate your claim. 


\subsection{A 13.56MHz RFID System based on Organic Transponders}

\author{
E. Cantatore'1, T. C. T. Geuns ${ }^{1}$, A. F. A Gruijthuijsen ${ }^{1}$, G. H. Gelinck', \\ S. Drews ${ }^{2}$, D. M. de Leeuw ${ }^{1}$
}

'Philips Research, Eindhoven, The Netherlands

${ }^{2}$ Philips Semiconductors, Hamburg, Germany

Electronics based on organic transistors is suited to the manufacture of RFID tags for retail applications [1] because of its lowcost, mechanical flexibility and the possibility it offers to integrate circuits with antennas on packaged items. Organic electronics [2] and antennas can be manufactured using low-cost high-volume technologies like printing. Still a convincing demonstration of the technical feasibility of organic RFID transponders is missing.

The RFID tags presented here are manufactured using a photolithographic bottom gate technology [3] on a $25 \mu \mathrm{m}$ thick plastic substrate. The $\mathrm{p}$-type semiconductor is pentacene, deposited from a precursor solution. Transistors consistently provide field-effect mobilities in the saturation region of $0.01 \mathrm{~cm}^{2} / \mathrm{Vs}$ and on/off current ratios of $10^{6}$.

A crucial element in any DC-powered tag (Fig. 15.2.1) is the rectifier, the only device that must work at the RF carrier frequency. In our technology the organic semiconductor is the top layer in the stack. Integration of a vertical diode [4] would require additional masks and process steps; therefore we chose to implement the integrated rectifier using diode-connected transistors.

The channel length of the transistors is typically $4 \mu \mathrm{m}$. As the mobility is $0.01 \mathrm{~cm}^{2} / \mathrm{Vs}$, one would expect a time of flight between source and drain of $160 \mathrm{~ns}$ at a $\mathrm{V}_{\mathrm{ds}}$ of $100 \mathrm{~V}$. Based on this simplistic estimation, a diode-connected transistor should operate correctly at the $125 \mathrm{kHz}$ RFID frequency but it should fail at $13.56 \mathrm{MHz}(\mathrm{T}=1 / \mathrm{f} \sim 74 \mathrm{~ns})$, the de-facto standard for item level identification.

When operating at $125 \mathrm{kHz}$, one has to choose carefully between capacitive and inductive antenna coupling (Fig. 15.2.1). At low frequencies the antenna must have large inductance and a low DC resistance $R_{L}$ to achieve a sufficient unloaded quality factor $\mathrm{Q}_{\mathrm{L}}\left(\mathrm{Q}_{\mathrm{L}}=\omega \mathrm{L} / \mathrm{R}_{\mathrm{L}}\right)$. To keep the antenna simple and cheap to manufacture, we preferred a capacitively coupled solution. Capacitive antennas can be produced with poorly conductive materials at low cost, but capacitive RFID systems lack the resonant tank on the tag and need close proximity between tag and reader to transfer to the tag a voltage sufficient to allow proper rectifier operation.

Two types of code generators were manufactured: the first produces a square wave (code A: ...101010...), the second a code that is easy to distinguish from a square wave (code B: ...101100...). Both tags use as rectifier two integrated diode-connected transistors (Fig. 15.2.1). The rectifier also acts as load modulator: the gate of the diode $\mathrm{M} 1$ is connected to GND or $\mathrm{V}_{\mathrm{dd}}$ in synchronism with the code, modulating the current absorbed by the tag. Code $\mathrm{A}$ is generated with a ring oscillator, code $\mathrm{B}$ is generated with a three flip-flop counter clocked by an integrated ring oscillator. Flip-flops, inverters and NAND gates used in the design are reported in [5].

The tags were successfully energized and read out through the capacitive antenna using a $125 \mathrm{kHz}$ carrier. A photograph of the reader and the tag, showing a code $\mathrm{B}$ on the oscilloscope, is presented in Fig. 15.2.2. The carrier on the reader antenna has a peak-to-peak value of $110 \mathrm{~V}$, generating a tag supply of $\mathrm{V}_{\mathrm{dd}}=-25 \mathrm{~V}$. The data rate is $700 \mathrm{~b} / \mathrm{s}$.

Once the feasibility of a RFID system based on organic transponders is demonstrated at $125 \mathrm{kHz}$, it is important to build organic tags able to generate codes with enough information for practical applications. Together with the code A and B tags we manufactured a tag with a $64 \mathrm{~b}$ code generator. To optimize testability, the architecture shown in Fig. 15.2.3 was chosen. In this chip a 64b hardwired memory matrix is read out by enabling each column of the matrix, one after the other, and reading a row at a time within the enabled column. At power-up, the two barrel connected shift registers receive a reset. In this state, only one flip-flop per shift register is set and the first row and column are enabled. The data $(1,1)$ is synchronized with the clock and passed to the Manchester encoder and to the modulator. Each subsequent clock acts on the row shift register (Fig. 15.2.3) and transfers the content of a new row within column 1 to the modulator. When a whole column is read, the following column is enabled and read out.

The $64 \mathrm{~b}$ code generator proved fully functional. The correct output code was measured at a $\mathrm{V}_{\mathrm{dd}}$ of $-30 \mathrm{~V}$ (Fig. 15.2.4). The data rate is $150 \mathrm{~b} / \mathrm{s}$. A chip micrograph is shown in Fig. 15.2.7; the chip contains 1938 transistors. The 64b code generators were also measured with the integrated rectifier-modulator; the tags work in air with a $\mathrm{V}_{\mathrm{ACpp}}$ voltage of $180 \mathrm{~V}$ at $125 \mathrm{kHz}$ generating the Manchester code.

In order to establish the limits of our system, the functionality of the rectifier at higher carrier frequencies was characterized. The DC output voltage $-V_{d d}$ as a function of the input peak-to-peak $A C$ voltage $\mathrm{V}_{\mathrm{ACpp}}$ is shown in Fig. 15.2.5. The rectifier works at frequencies beyond $20 \mathrm{MHz}$, far above the limits expected from the simplistic time of flight estimation. The reason for this excellent behavior is attributed to the fact that mobility in organic semiconductors is a power function of the applied gate-source voltage [6] and the rectifiers are operated at large $\mathrm{V}_{\mathrm{gs}}$.

A system capable of generating the $13.56 \mathrm{MHz}$ carrier and to readout the tags via the capacitive antenna was built. This system could successfully energize and readout code A and code B tags at 13.56MHz. The measured output codes are shown in Fig. 15.2.6; the bit rate is $1 \mathrm{~kb} / \mathrm{s}$ for code $\mathrm{A}$ and $700 \mathrm{~b} / \mathrm{s}$ for code $\mathrm{B}$. At this carrier frequency an inductive RF link could be advantageously used to increase the range of the RFID system.

Repeated exposure, in air, of the tags to the $\mathrm{AC}$ voltage needed to generate sufficient DC supply did not result in measurable performance degradation.

In summary, a complete RFID system has been presented working at $13.56 \mathrm{MHz}$, the current standard for item level RF identification, which is able to distinguish between two tags manufactured with organic transistors. Also reported are functional organic $64 \mathrm{~b}$ transponders. All measurements presented have been obtained in air. These results demonstrate the technical feasibility of commercially relevant RF identification systems based on organic tags.

\section{Acknowledgements:}

Authors thank L. Apollonio, Politecnico di Bari and A. Mühlberg, Technical University of Hamburg for their collaboration. The funding of BMBF (project Politag) and the EC (project PolyApply IST-IP-507143) is gratefully acknowledged.

\section{References:}

[1] C. M. Hart et al., "Low-Cost All-Polymer Integrated Circuits," Proc. ESSCIRC, pp.30-34, Sept., 1998.

[2] A. Knobloch et al., "Fully printed integrated circuits from solution processable polymers," Jour. Appl. Phys., vol. 96, no. 4, pp. 2286-2291, 2004.

[3] D.M. de Leeuw et al., "Polymeric integrated circuits: fabrication and first characterization," Proc. IEDM, pp. 293-296, Dec., 2002.

[4] S. Steudel et al., "50 MHz rectifier based on an organic diode", Nature Mat. 4, pp. 597-600, 2005

[5] E. Cantatore et al., "Circuit Yield of Organic Integrated Electronics," ISSCC Dig. Tech. Papers, pp. 380-381, Feb. 2003.

[6] M.C.J.M. Vissenberg and M.Matters, "Theory of the field-effect mobility in amorphous organic transistors", Phy. Rev. B, vol. 57 no.20, pp. 1296412967, 1998. 

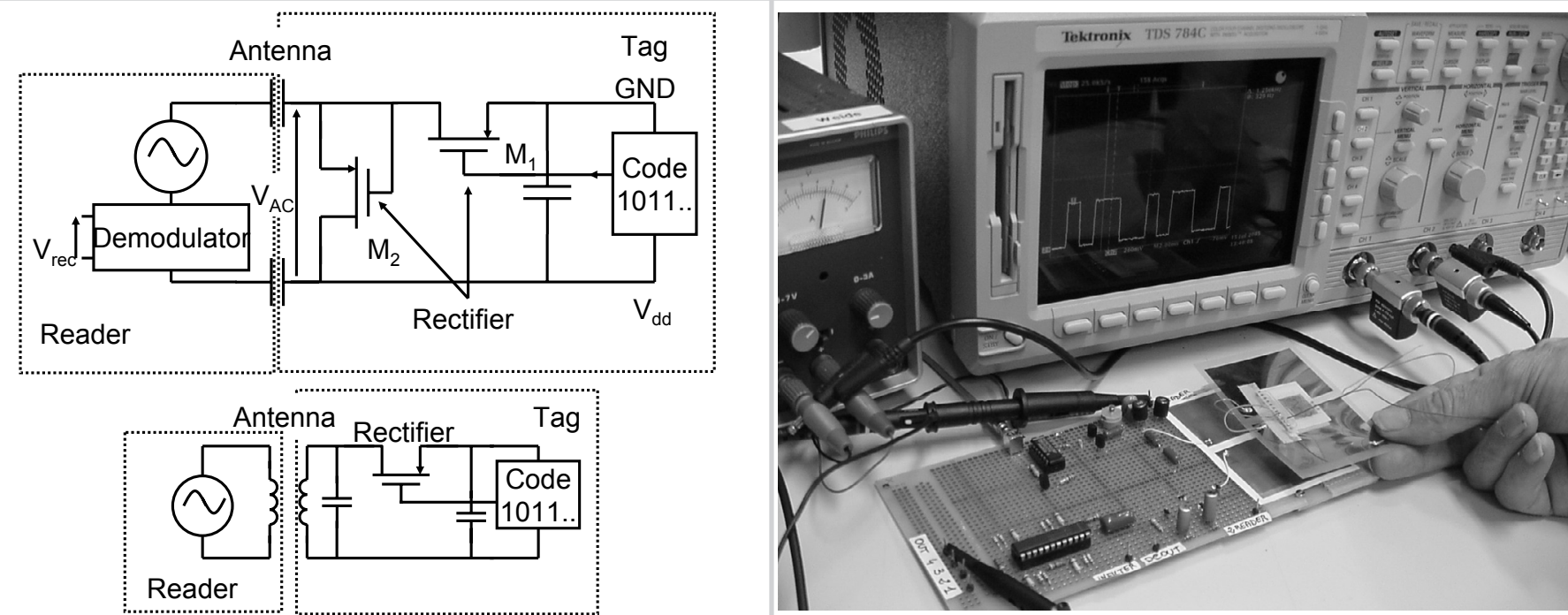

Figure 15.2.1: Capacitively and inductively coupled organic tags with integrated rectifiers.

Figure 15.2.2: A code B tag is energized and readout at $125 \mathrm{kHz}$ using a base station and an oscilloscope.

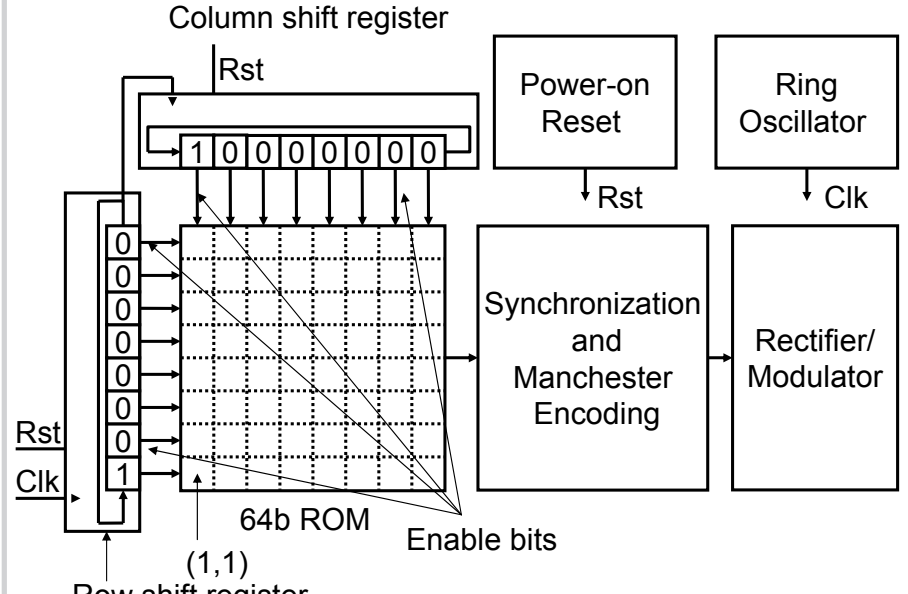

Row shift register

Figure 15.2.3: The 64b code generator architecture (reset state).

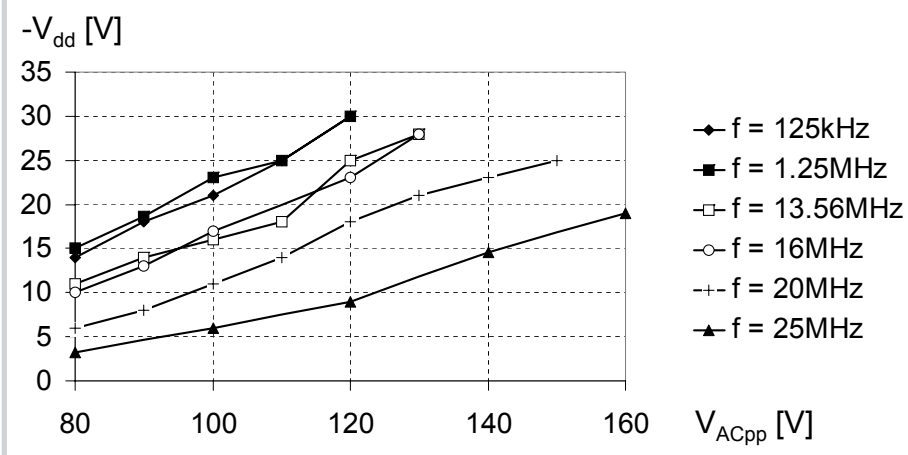

Figure 15.2.5: $D C$ output voltage $-V_{\mathrm{dd}}$ of the integrated organic rectifier as a function of the input peak-to-peak $A C$ voltage $V_{A C p p}$ at different frequencies.

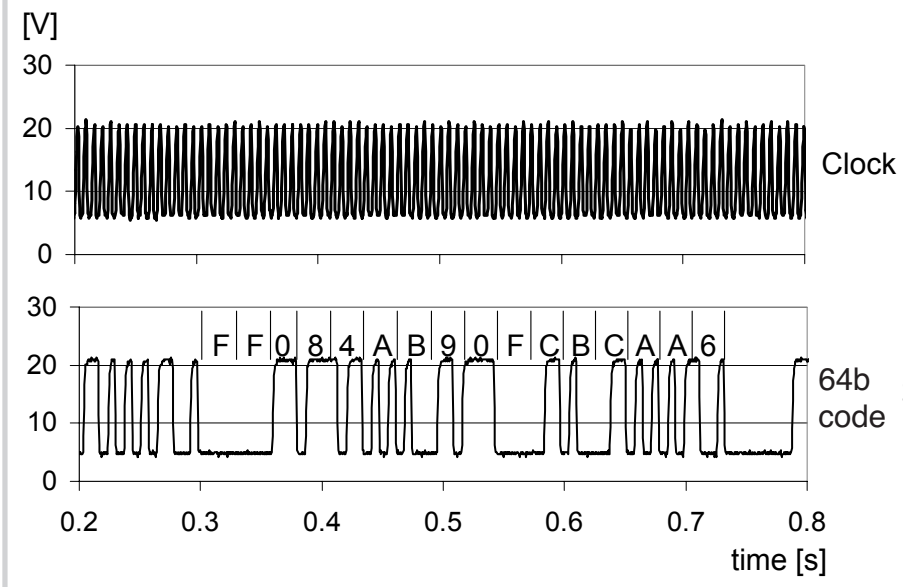

Figure 15.2.4: Signals measured on the $64 \mathrm{~b}$ code generator at $V_{d d}=-30 \mathrm{~V}$. The programmed code is shown in hexadecimal together with the generated code signal.

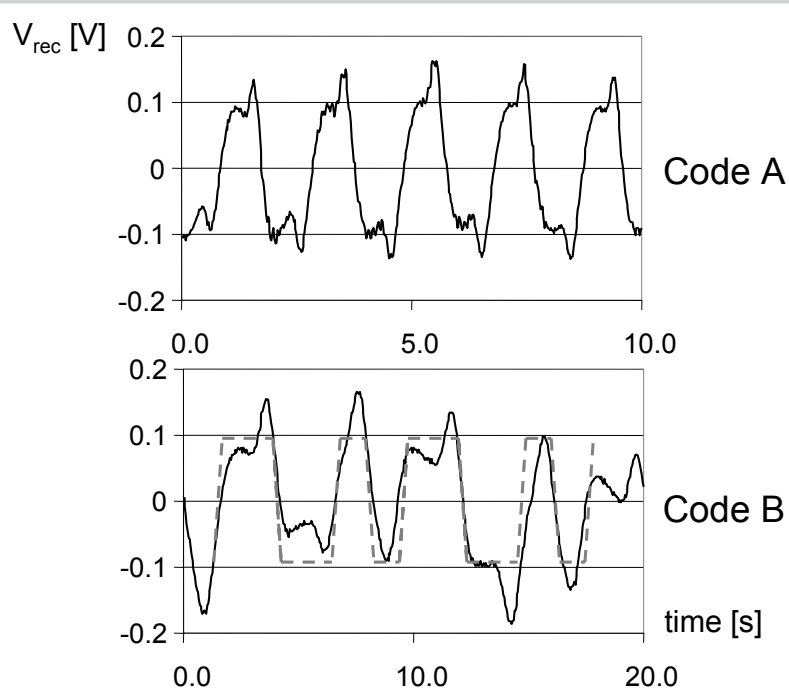

Figure 15.2.6: Output codes of a code A and a code B tag readout using a $13.56 \mathrm{MHz}$ carrier through a capacitive antenna. 
ISSCC 2006 / SESSION 15 / ORGANIC DEVICES AND CIRCUITS / 15.2

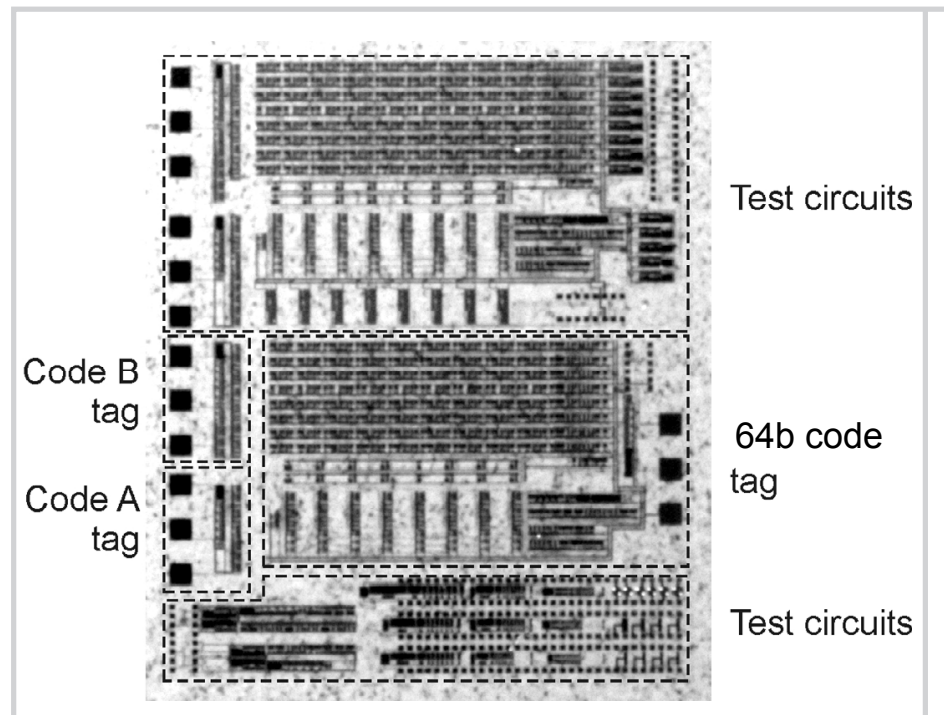

Figure 15.2.7: Micrograph of the reticle containing all organic tags. 


\section{Antenna}

Tag
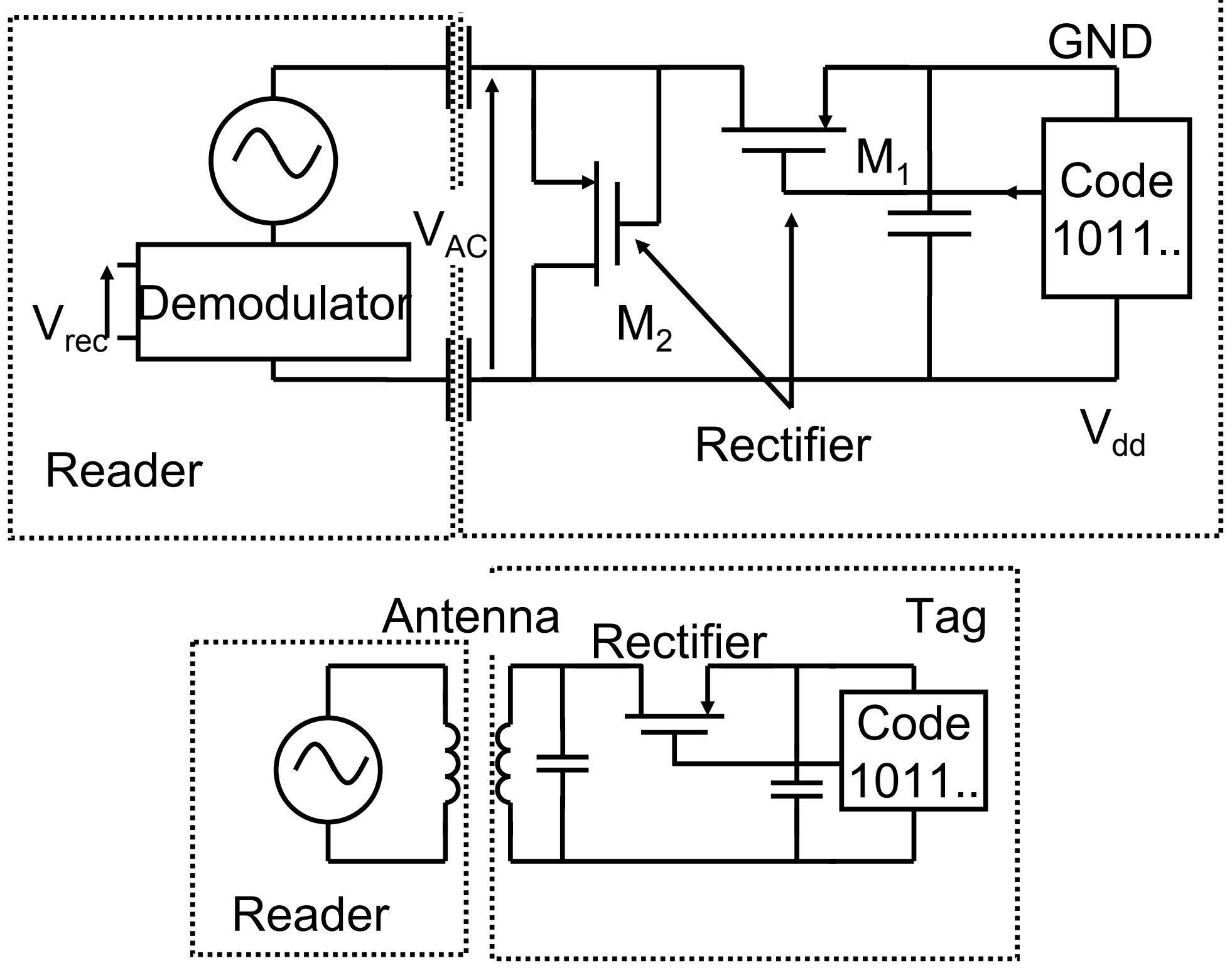

Figure 15.2.1: Capacitively and inductively coupled organic tags with integrated rectifiers. 


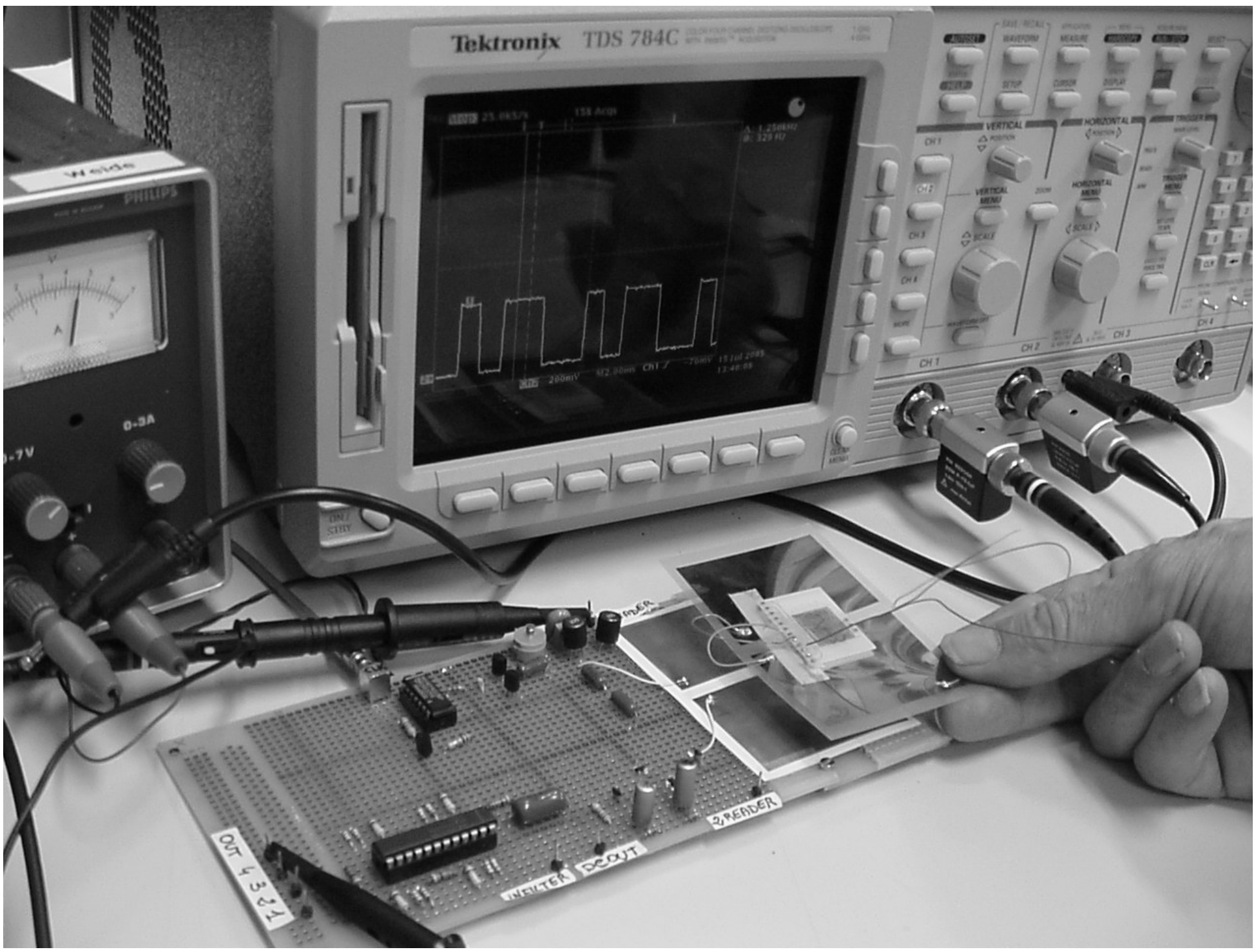

Figure 15.2.2: A code B tag is energized and readout at 125kHz using a base station and an oscilloscope. 


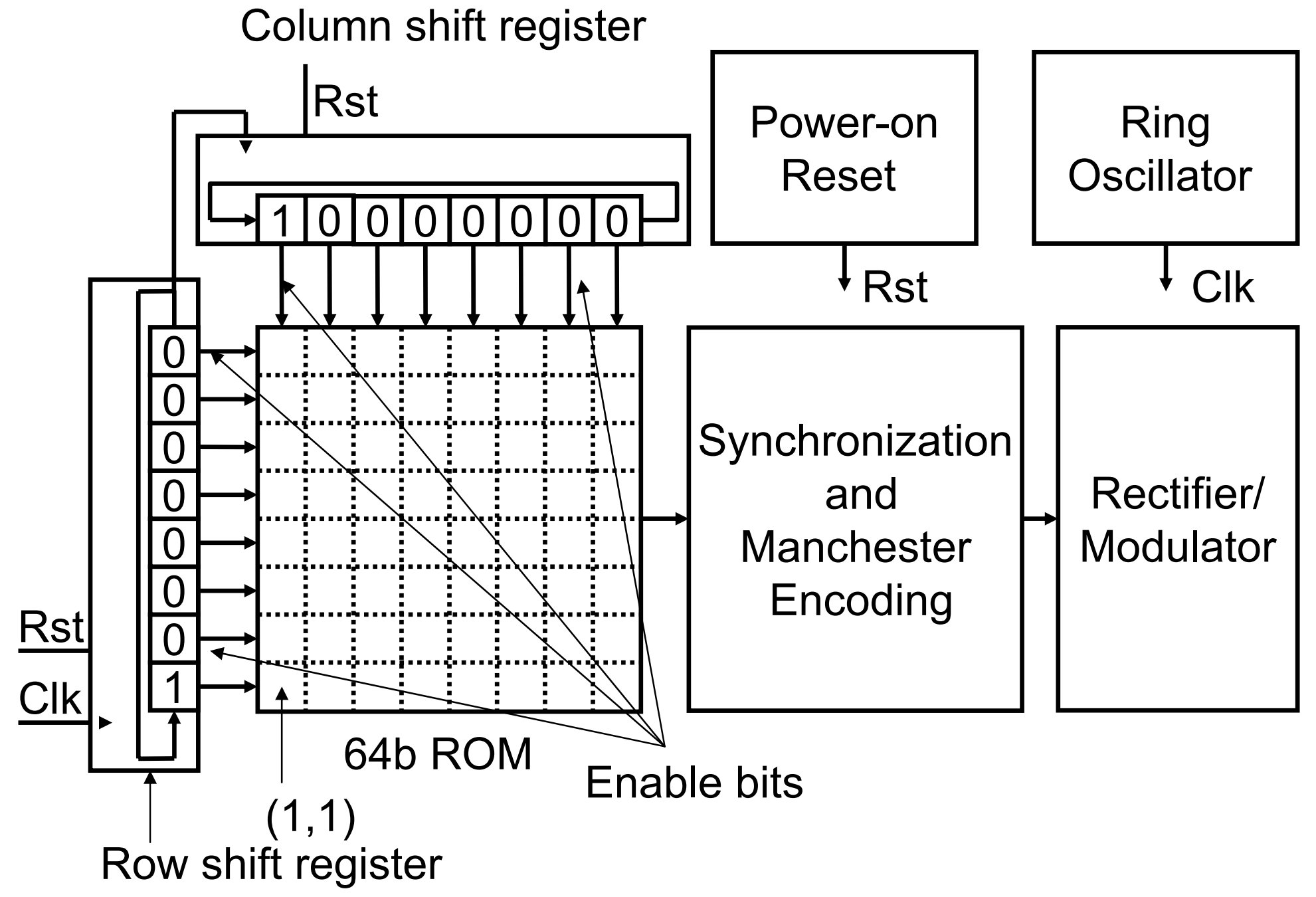

Figure 15.2.3: The 64b code generator architecture (reset state). 


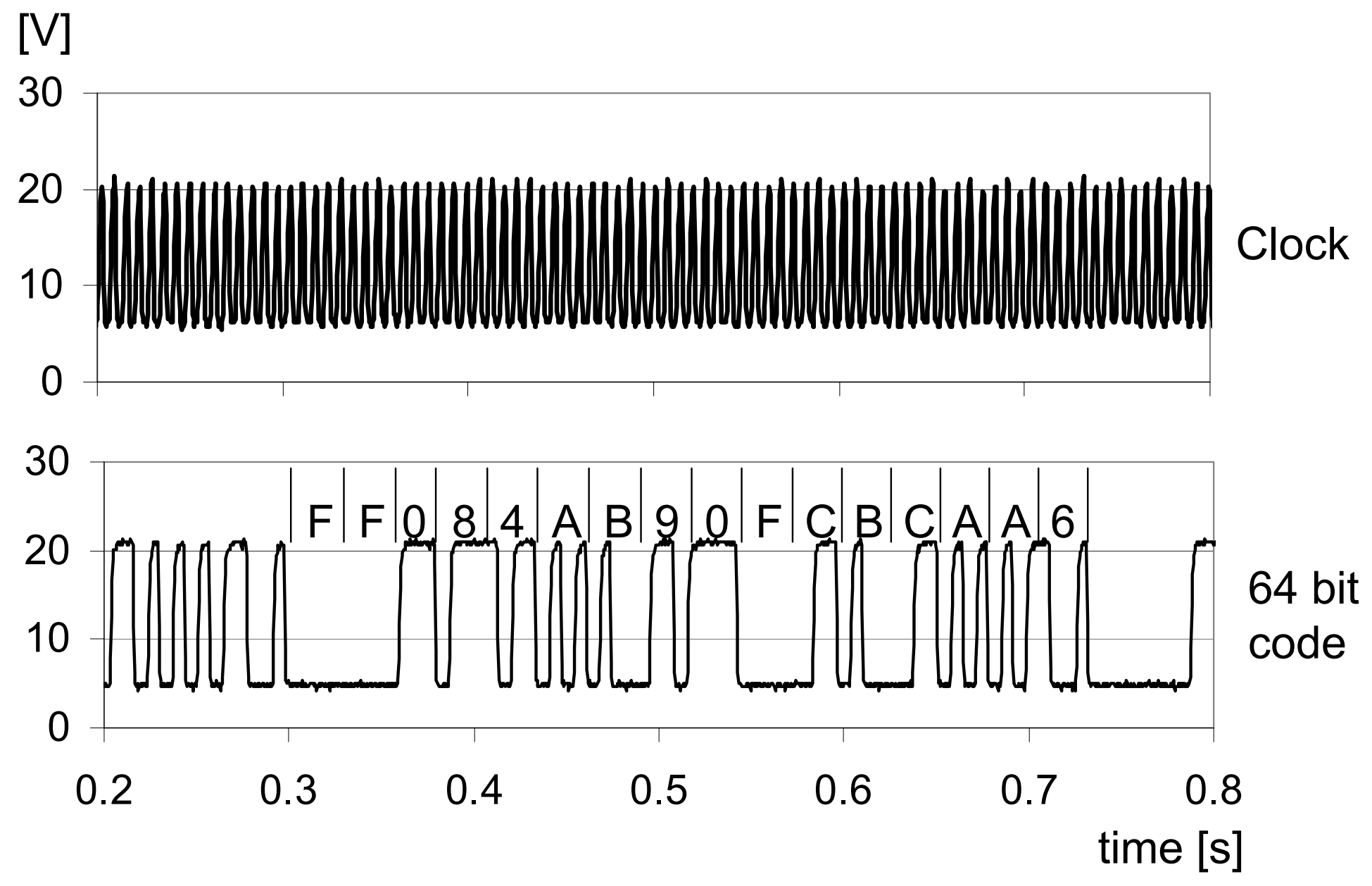

Figure 15.2.4: Signals measured on the $64 \mathrm{~b}$ code generator at $V_{d d}=-30 \mathrm{~V}$. The programmed code is shown in hexadecimal together with the generated code signal. 
$-\mathrm{V}_{\mathrm{dd}}[\mathrm{V}]$

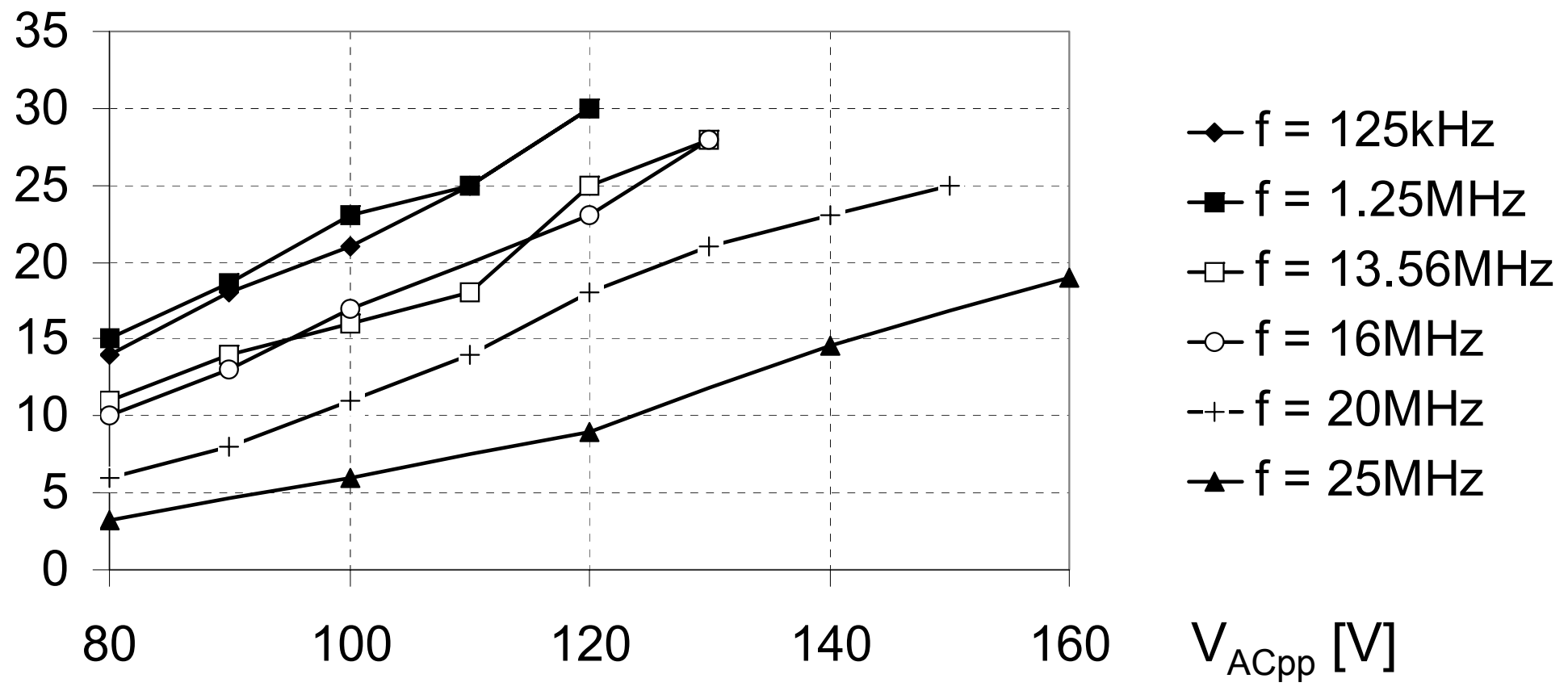

Figure 15.2.5: $D C$ output voltage $-V_{\text {dd }}$ of the integrated organic rectifier as a function of the input peak-to-peak $A C$ voltage $V_{\text {ACpp }}$ at different frequencies. 


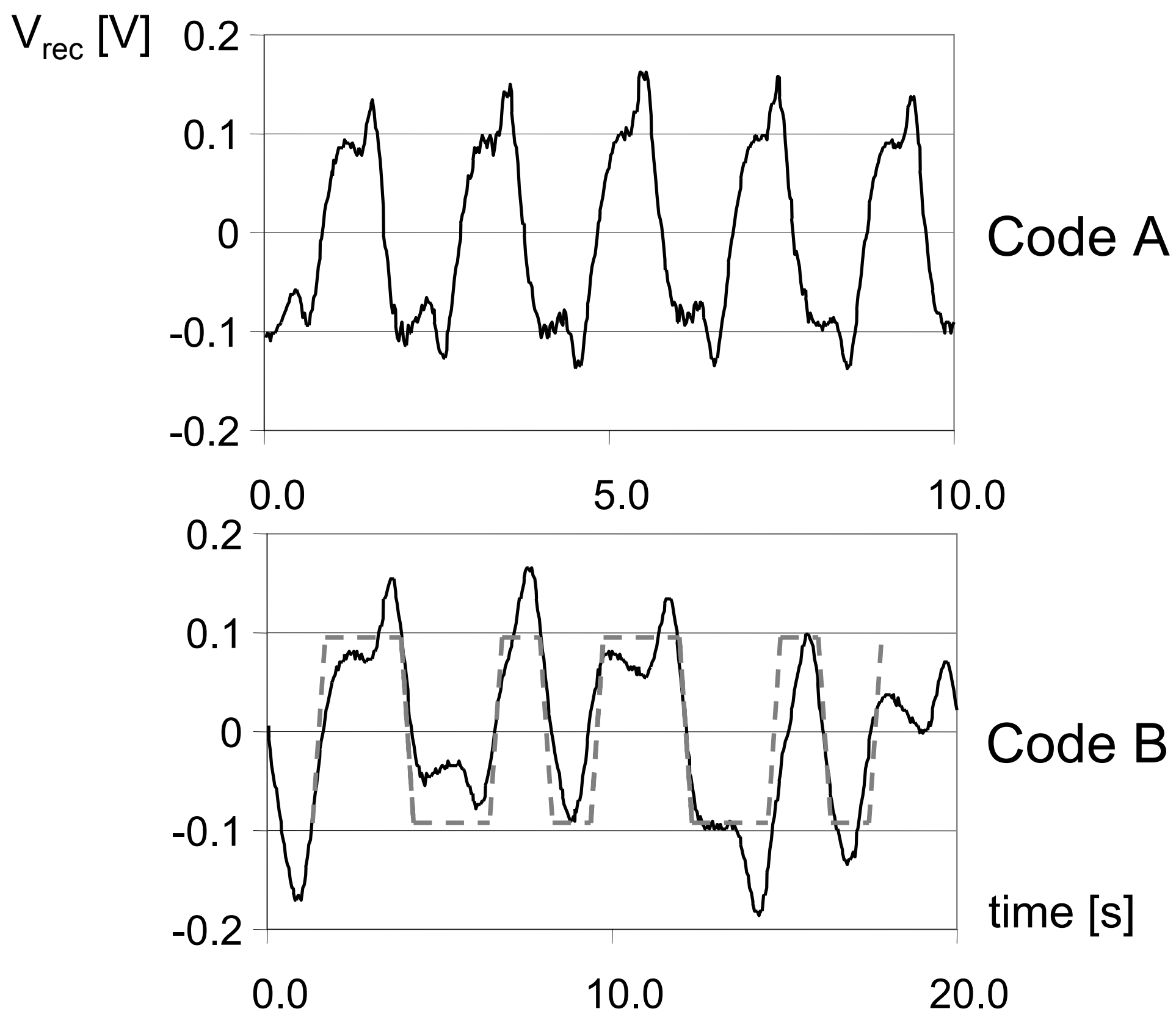

Figure 15.2.6: Output codes of a code A and a code B tag readout using a $13.56 \mathrm{MHz}$ carrier through a capacitive antenna. 


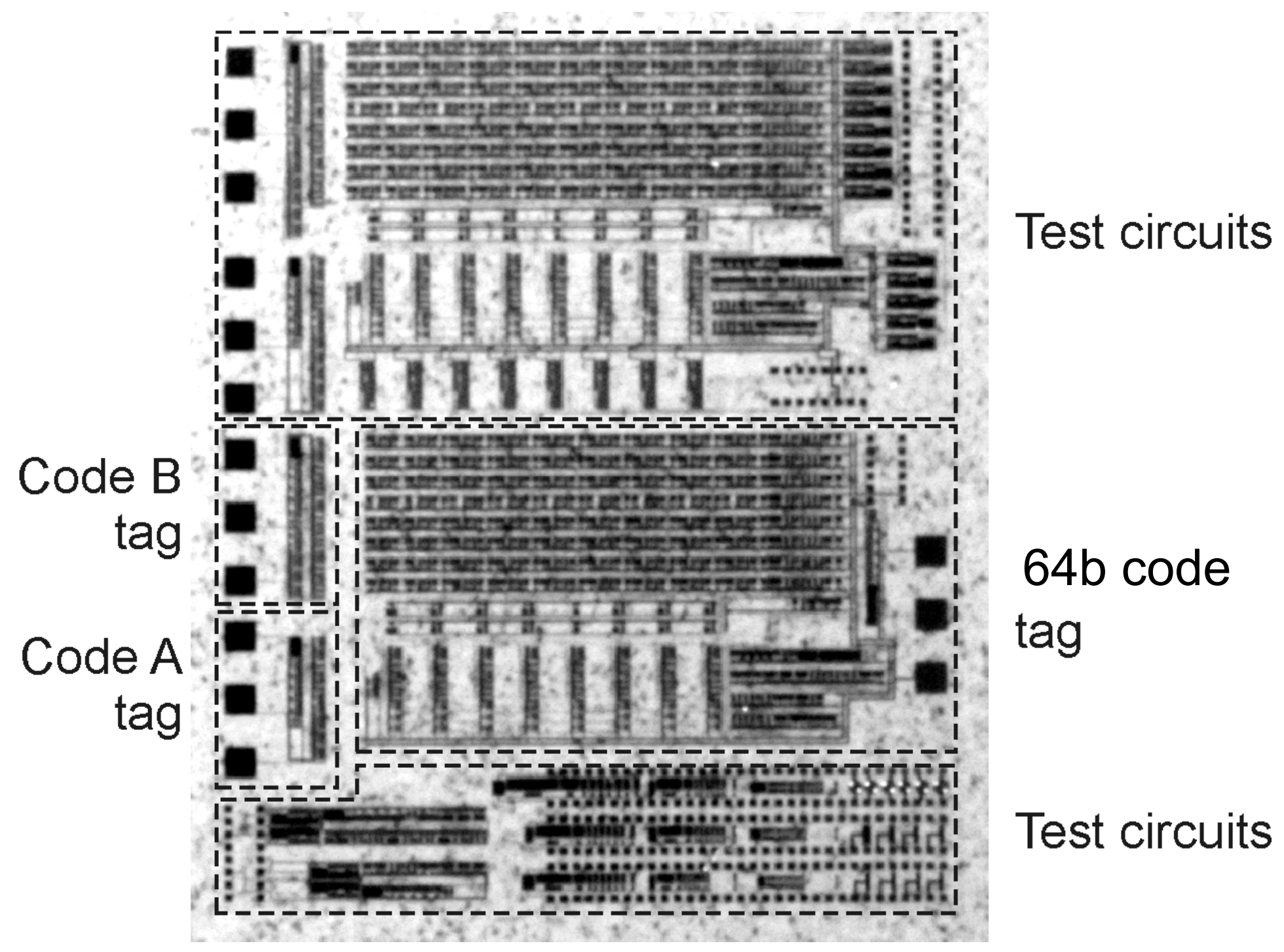

Figure 15.2.7: Micrograph of the reticle containing all organic tags. 